\title{
Programmed Cell Death of Adult-Generated Hippocampal Neurons Is Mediated by the Proapoptotic Gene Bax
}

\author{
Woong Sun, ${ }^{1,2}$ Adam Winseck, ${ }^{1}$ Sharon Vinsant, ${ }^{1}$ Ok-hee Park, ${ }^{2}$ Hyun Kim, ${ }^{2}$ and Ronald W. Oppenheim ${ }^{1}$ \\ ${ }^{1}$ Department of Neurobiology and Anatomy and Neuroscience Program, Wake Forest University School of Medicine, Winston-Salem, North Carolina \\ 27157, and 2Department of Anatomy, Brain Korea 21, Korea University College of Medicine, Sungbuk-Gu, Seoul, Korea 136-705
}

In the dentate gyrus (DG) of the adult mouse hippocampus, a substantial number of new cells are generated daily, but only a subset of these survive and differentiate into mature neurons, whereas the majority undergo programmed cell death (PCD). However, neither the intracellular machinery required for adult stem cell-derived neuronal death nor the biological implications of the significant loss of these newly generated cells have been examined. Several markers for apoptosis failed to reveal cell death in Bax-deficient mice, and this, together with a progressive increase in neuron number in the DG of the Bax knock-out, indicates that Bax is critical for the PCD of adult-generated hippocampal neurons. Whereas the proliferation of neural progenitor cells was not altered in the Bax-knock-out, there was an accumulation of doublecortin, calretinin ${ }^{+}$, and neuronal-specific nuclear protein ${ }^{+}$postmitotic neurons, suggesting that Baxmediated PCD of adult-generated neurons takes place during an early phase of differentiation. The absence of PCD in the adult also influenced the migration and maturation of adult-generated DG neurons. These results suggest that PCD in the adult brain plays a significant role in the regulation of multiple aspects of adult neurogenesis.

Key words: adult neurogenesis; Bax; cell death; mouse; proliferation; migration; differentiation

\section{Introduction}

During embryonic development, one-half or more of all newly generated neurons undergo programmed cell death (PCD) after making provisional contacts with targets and afferents (Oppenheim, 1991). Neurogenesis and subsequent PCD persists in certain areas of the adult brain (Kaplan and Hinds, 1977; Kaplan et al., 1985; Eriksson et al., 1998; Kornack and Rakic, 1999; Biebl et al., 2000; Horner et al., 2000; Cameron and McKay, 2001; Winner et al., 2002; Zhao et al., 2003). In the dentate gyrus (DG) of the adult rat hippocampal formation, $\sim 10,000$ cells are generated daily, whereas $60-80 \%$ of the newly generated cells degenerate within 1 month after their production (Cameron and McKay, 2001; Dayer et al., 2003). The precise control of the production and elimination of adult-generated neurons is thought to be critical for the maintenance of a relatively constant number of neurons in the adult nervous system and for the regulation of adult brain function. Several environmental influences are known to be involved in the regulation of PCD of adult-generated neurons. For example, environmental stress has been reported to enhance PCD (Gould et al., 1997), whereas exposure to an enriched environment, the occurrence of specific types of learning, and afferent synaptic activity can result in the increased survival of adult-

Received Nov. 28, 2003; revised Nov. 1, 2004; accepted Nov. 1, 2004

This work was supported by National Institutes of Health Grant NS20402 (R.W.O.) and by the Korean Ministry of Science and Technology via 21C Frontier Brain Research (enter Grant M103KV010018-03K2201-01820 (H.K.).

Correspondence should be addressed to Dr. Woong Sun, Department of Anatomy, Brain Korea 21, Korea University College of Medicine, Anam-Dong, Sungbuk-Gu, Seoul, Korea 136-705. E-mail: woongsun@korea.ac.kr. DOI:10.1523/JNEUROSCI.1436-04.2004

Copyright $\odot 2004$ Society for Neuroscience ～0270-6474/04/2411205-09\$15.00/0 generated neurons (Kempermann et al., 1997; Young et al., 1999; Petreanu and Alvarez-Buylla, 2002). However, currently neither the precise biochemical pathways nor the physiological relevance of PCD of adult-generated neurons is known.

It has been demonstrated recently that target-dependent PCD of neurons during embryonic development is mediated by Bax, a proapoptotic member of the Bcl-2 family (Deckwerth et al., 1996; White et al., 1998; Sun and Oppenheim, 2003; Sun et al., 2003). For example, Bax knock-out (KO) mice do not exhibit developmental PCD of dorsal root ganglion sensory neurons, superior cervical ganglion sympathetic neurons, or motoneurons (MNs) (Deckwerth et al., 1996; White et al., 1998; Lentz et al., 1999; Sun et al., 2003). Although it has been suggested that the survival of adult-generated neurons may be regulated by the same mechanisms acting during development (Kintner, 2002), little direct evidence is available. The data presented here clearly indicate that PCD in the adult hippocampus is virtually absent or greatly reduced in Bax-KO mice, and, therefore, similar to the PCD of neurons during development, a Bax-dependent pathway is essential for the PCD of adult-generated neurons. To assess the significance of the PCD of adult-generated neurons, we further examined the proliferation of neural progenitor cells and the migration and differentiation of adult-generated DG neurons in the absence of PCD.

\section{Materials and Methods}

Animals. Heterozygous Bax-deficient mice were maintained on a C57BL/6 background. Sibling animals were collected and individually genotyped by PCR as described previously (Knudson et al., 1995). For 
bromodeoxyuridine (BrdU) labeling, 3-month-old adult mice were injected intraperitoneally with a BrdU solution ( $50 \mu \mathrm{g} / \mathrm{gm}$ body weight) once daily for 5 consecutive days. In an attempt to completely label adult-generated neurons, a higher concentration of BrdU $(200 \mu \mathrm{g} / \mathrm{gm}$ body weight) was used in some experiments (Cameron and McKay, 2001). To label a cohort of developmentally generated DG neurons, BrdU (50 $\mu \mathrm{g} / \mathrm{gm}$ body weight) was administered once on postnatal day 3 .

Histology. To identify cells dying by apoptosis, DNA fragmentation was visualized by the terminal deoxynucleotidyl transferase-mediated biotinylated UTP nick end labeling (TUNEL) method, as described previously (Oppenheim et al., 2001). For immunohistochemical analysis, animals were perfused with $4 \%$ paraformaldehyde, and the brains were postfixed in the same fixative for $24 \mathrm{hr}$. Brains were then cryoprotected in $30 \%$ sucrose and sectioned $(40 \mu \mathrm{m})$, and subsequent immunostaining was performed by the free-floating method. For BrdU staining, sections were incubated with $0.1 \mathrm{~N} \mathrm{HCl}$ for $1 \mathrm{hr}$ at $37^{\circ} \mathrm{C}$, washed with PBS, and blocked with $5 \%$ goat serum and $0.1 \%$ Triton X-100 in PBS for 30 min. The following primary antibodies were applied overnight: anti-BrdU, 1:10,000; anti-activated caspase-3, 1:200 (Cell Signaling Technology, Beverly, MA); anti-Bax, 1:500 (PharMingen, San Diego, CA); antidoublecortin (DCX), 1:1000; anti-polysialylated neural cell adhesion molecule (PSA-NCAM), 1:500 (Chemicon, Temecula, CA); anticalretinin (CR), 1:1000 (Swant, Bellinzona, Switzerland); anti-neuronalspecific nuclear protein (NeuN), 1:10,000 (Calbiochem, La Jolla, CA); anti-GFAP, 1:25,000 (Sigma, St. Louis, MO); anti-calbindin (CB), 1:10,000 (Sigma); anti-phospho-histone H3, 1:1000 (Upstate Biotechnology, Lake Placid, NY); and anti-proliferating cell nuclear antigen (PCNA), 1:200 (DakoCytomation, Carpinteria, CA). After several washes with PBS, appropriate secondary antibodies were applied for 30 min. Subsequently sections were washed, mounted, and observed with a fluorescence or confocal microscope.

Cell counts. For quantification of DG neuron numbers, animals were immersion fixed in Bouin's solution, processed, embedded in paraffin, sectioned $(8-10 \mu \mathrm{m})$ serially, and stained with thionin. The volume of the DG was assessed by areal quantification in every fifth section through the DG. To assess neuronal density, at least three different regions $(50 \times$ $50 \mu \mathrm{m}$ ) were chosen from each section, and sections from at least three different levels of the DG were examined. DG cells containing a clear nucleolus, nucleus, and cytoplasm were included in the counts as described previously (Clarke and Oppenheim, 1995), and the mean values of the number of cells within the counting area were calculated. The total number of DG neurons was obtained by multiplication of the DG volume by neuronal density.

For BrdU counts, both dark-labeled and light-labeled cells (see Fig. $3 C$ ) located in the granule cell layer (GCL) were separately counted in every sixth section $(40 \mu \mathrm{m})$. Because there were substantial differences in the intensity of BrdU-IR, we categorized cells as either dark or light labeled. Dark-labeled cells were those with dense BrdU-IR evenly distributed in the entire nucleus, and light-labeled cells were those that exhibited a less dense and punctate pattern of IR within the nucleus. $\mathrm{BrdU}^{+}$ cells located $>50 \mu \mathrm{m}$ from the border of the GCL were excluded from the counts. The number of PCNA, DCX, or CR-immunoreactive cells was obtained by the summation of all immunoreactive cells in every sixth section $(40 \mu \mathrm{m})$ containing the dentate gyrus, and the counted numbers were corrected by the use of Abercrombie's correction factor, which is defined as $M /(M+L)$, where $M$ is the thickness of the section, and $L$ is the mean value of the height of the cells counted (Abercrombie, 1946; Guillery and Herrup, 1997). $M$ and $L$ were measured from three different randomly selected DG regions per each animal using a Zeiss (Oberkochen, Germany) LSM confocal microscope with Z-scan.

In situ hybridization. The brains from 2-month-old mice were dissected, snap frozen, and sectioned horizontally $(14 \mu \mathrm{m})$. Sections were then postfixed in $4 \%$ paraformaldehyde, acetylated, and prehybridized for $2 \mathrm{hr}$ at room temperature. $\mathrm{S}^{35}$-labeled probes for mouse Bax were in vitro transcribed from the Bax cDNA fragment containing nucleotides 226-579 (GenBank accession number L22472) in pBS-SK(+) vector. The sections were hybridized with the labeled probes $\left(1.2 \times 10^{6} \mathrm{cpm} /\right.$ slide) at $52^{\circ} \mathrm{C}$ overnight, followed by four washes in $4 \times$ SSC solution at room temperature. The slides were then incubated with RNase buffer

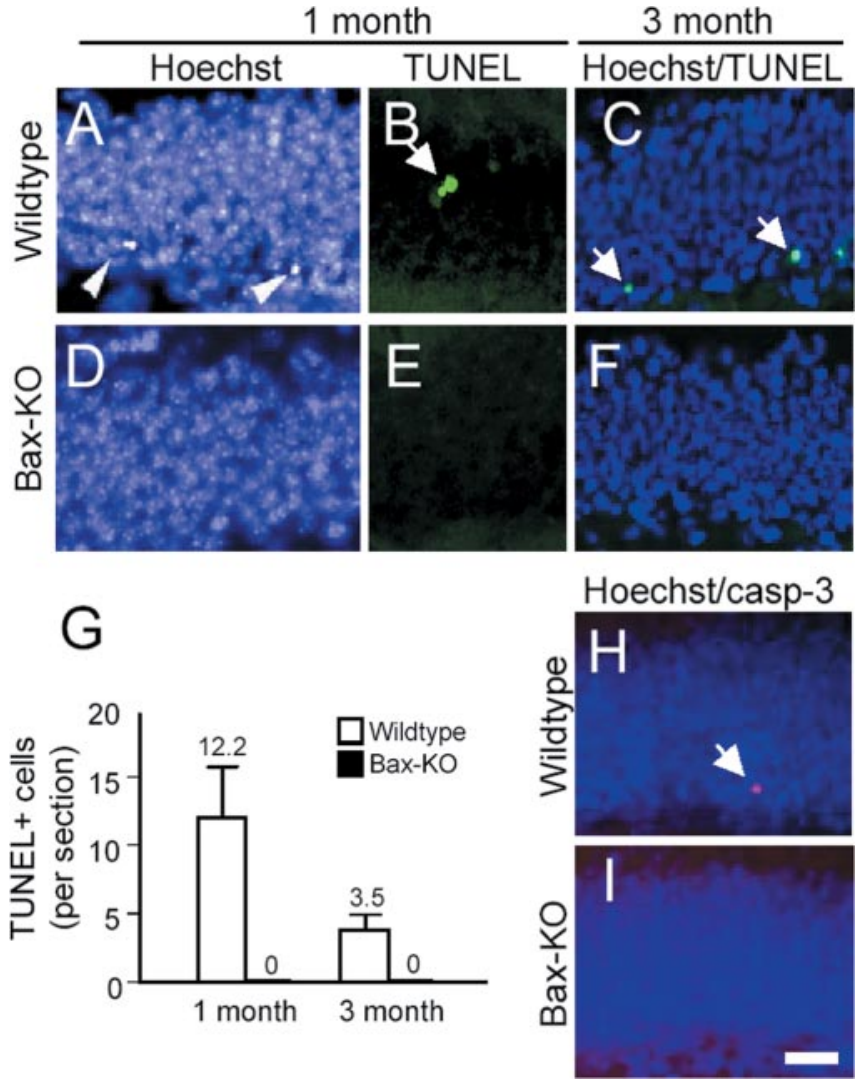

Figure 1. The absence of apoptosis in adult DG of Bax-KO mice. Apoptotic cells were analyzed in situ by condensed nuclei $(A, C, D, F)$ brightly stained by Hoechst (arrowheads), DNA fragmentation ( $B, E$, TUNEL, green, arrow), or activated caspase-3 (casp-3) immunostaining $(H$, $I$, red, arrow) from adult (1- or 3-month-old) WT versus Bax-K0 mice. Scale bar, $50 \mu \mathrm{m}$. Three animals in each group and at least five sections from each individual were examined for quantification $(G)$.

[RNase A ( $10 \mathrm{mg} / \mathrm{ml}$ in distilled water), $0.5 \mathrm{M} \mathrm{NaCl}, 10 \mathrm{~mm}$ Tris- $\mathrm{HCl}$, and $1 \mathrm{~mm}$ EDTA, $\mathrm{pH} 8.0$ ] at $37^{\circ} \mathrm{C}$ for $30 \mathrm{~min}$. After RNase treatment, slides were washed with $2 \times$ SSC $-10 \mathrm{~mm}$ DTT (twice for $5 \mathrm{~min}$ ), $1 \times$ SSC $-10 \mathrm{~mm}$ DTT for $10 \mathrm{~min}, 0.5 \times$ SSC $-10 \mathrm{~mm}$ DTT for $10 \mathrm{~min}$, and $0.1 \times$ SSC -10 mM DTT for $30 \mathrm{~min}$ at $62^{\circ} \mathrm{C}$. Finally, the sections were dehydrated, air dried, and exposed to X-ray film (BioMAX-MR; Eastman Kodak, Rochester, NY) for $5 \mathrm{~d}$.

\section{Results}

\section{Absence of PCD in the adult neurogenic regions of} Bax-KO mice

We first examined whether PCD in the adult DG of the hippocampal formation is influenced by Bax deletion (Fig. 1). In the DG of 1-month-old wild-type (WT) mice, chromosomal condensation and $\mathrm{TUNEL}^{+}$cells (indices of PCD) were readily observed near the subgranular zone (SGZ), in which adult neural stem-progenitor cell proliferation takes place. In contrast, condensed nuclei or $\mathrm{TUNEL}^{+}$cells were never found in Bax-KO mice. At 3 months, WT mice exhibited some TUNEL ${ }^{+}$cells (but the number of labeled cells appeared to be reduced compared with 1-month-old WT mice), whereas no $\mathrm{TUNEL}^{+}$cells were observed in the DG of Bax-KO mice. Similarly, we found cleaved caspase-3-immunoreactive cells only in the DG of WT but not Bax-KO mice (Fig. 1, compare $H, I$ ). Consistent with these observations, we found that substantial amounts of Bax mRNA and protein were detected in the adult WT DG (Fig. 2D); a subset of DG cells appeared to express higher levels of Bax. These Bax ${ }^{+}$ cells possessed dendrite-like neuritic processes, which were mor- 


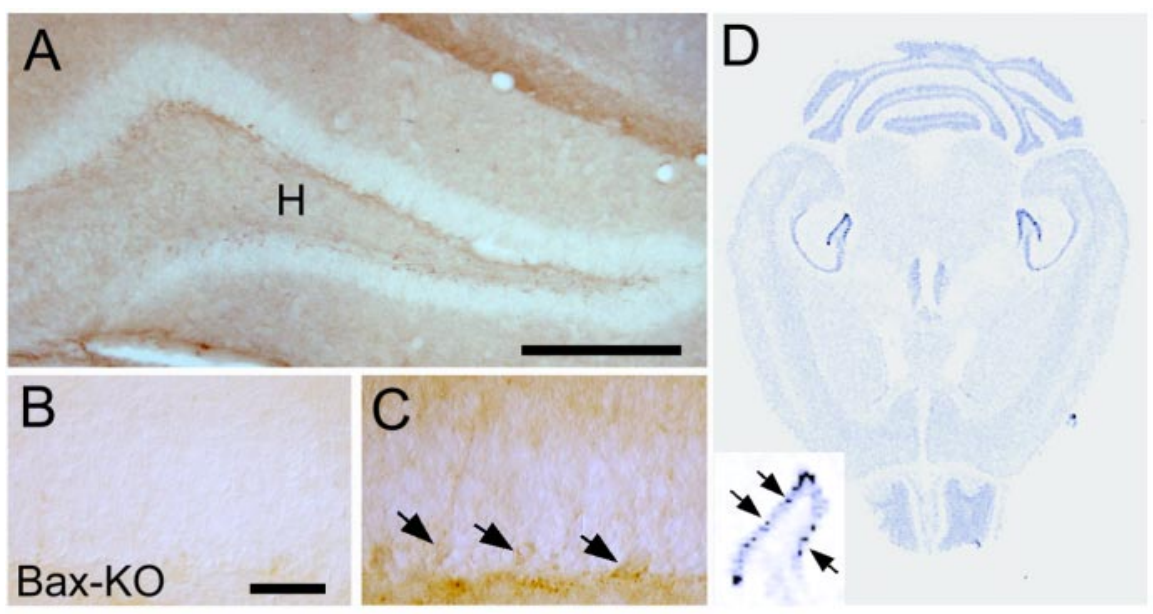

Figure 2. Bax-IR in the DG of 2-month-old WT mice $(A)$. Note that weak but significant Bax-IR was observed in a subset of cells localized in the SGZ (C, arrows). $H$ indicates the hilar region of the hippocampal formation. Bax-KO DG did not show significant Bax- $I R(B)$. DG from three independent animals were observed, and a representative image is shown. D, In situ hybridization of $B a x$ mRNA in the adult (2-month-old) WT mouse. Enlarged image of the DG shows a subset of cells that express higher amounts of $B$ ax mRNA. Scale bars: $A, 500 \mu \mathrm{m} ; B, C, 50 \mu \mathrm{m}$.

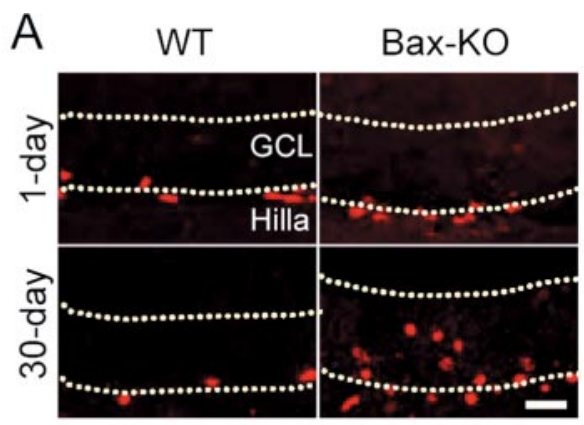

\section{B}

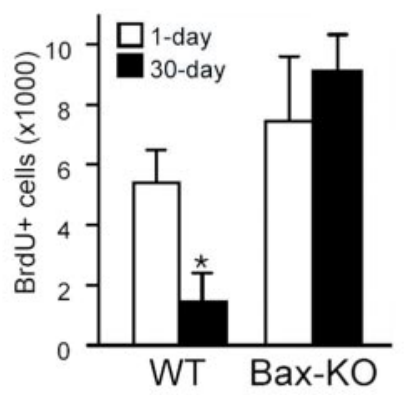

C

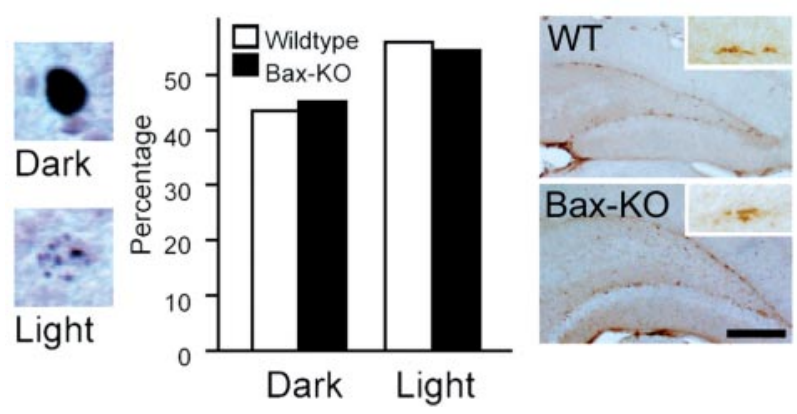

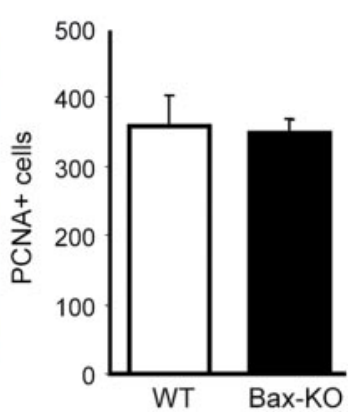

Figure 3. Normal production of new neurons in the absence of adult PCD. $A$, After five consecutive daily injections of BrdU ( 50 $\mu \mathrm{g} \cdot \mathrm{gm}^{-1} \cdot \mathrm{d}^{-1}$ ) to 3-month old WT and Bax-KO mice, BrdU ${ }^{+}$cells were immunostained after $1 \mathrm{~d}(A$, top row) or $30 \mathrm{~d}$ survival ( $A$, bottom row). Dotted lines mark the borders of the $\mathrm{GCL}$. Scale bar, $50 \mu \mathrm{m}$. B, Quantification of BrdU ${ }^{+}$cells in 1 and $30 \mathrm{~d}$ survival group after BrdU injection in 3-month-old Bax-KO mice. $n=3$; ${ }^{*} p<0.05$ in $t$ test comparison of WT versus Bax-K0 mice. C, Percentage of dark-labeled or light-labeled $\mathrm{BrdU}^{+}$cells in the $30 \mathrm{~d}$ survival group from WT and Bax-KO mice. Examples of dark-stained (top) and light-stained (bottom) cells are on the left. D, Immunohistochemistry of PCNA, which is a marker for proliferating cells. Insets show a cluster of PCNA ${ }^{+}$cells in the SGZ. The number of PCNA ${ }^{+}$cells was similar in the two groups. Sum of PCNA ${ }^{+}$cell numbers from every sixth section of individual animals were quantified; $n=4$. Scale bar, $500 \mu \mathrm{m}$.

phologically similar to immature early postmitotic neurons. Accordingly, the population undergoing PCD in the adult DG are most likely postmitotic, early differentiating neurons. Collectively, these results indicate that PCD of the SGZ cells in the adult $\mathrm{DG}$ is absent or greatly reduced in Bax-KO mice.
Production of new cells in the adult DG is not modified after the prevention of adult PCD by Bax deletion

Next, we examined whether the prevention of adult PCD influences the production of new cells. To address this, we performed daily injections of $\operatorname{BrdU}$ (50 $\mu \mathrm{g} / \mathrm{gm}$ body weight) into 3-month-old mice for 5 consecutive days and compared the number of BrdU ${ }^{+}$cells $1 \mathrm{~d}$ after the last BrdU injection (Fig. 3A,B). Approximately 6000 cells were $\mathrm{BrdU}^{+}$in the SGZ of 3-month-old WT mice $1 \mathrm{~d}$ after the last BrdU injection, and a similar number of $\mathrm{BrdU}^{+}$cells was observed in Bax-KO littermates, suggesting that the initial production of new cells is not influenced by Bax deletion. Some animals received a single BrdU injection of $200 \mu \mathrm{g} / \mathrm{gm}$ body weight. This dose of BrdU is reported to more completely label DNA synthesizing cells in situ (Cameron and McKay, 2001), although high concentrations of BrdU have been reported to be toxic (Sekerkova et al., 2004). Using this protocol, we again obtained no apparent difference in the number of $\mathrm{BrdU}^{+}$cells between WT and Bax-KO mice ( 3150 cells in WT mice, and 2870 cells in Bax-KO mice; $n=1$ in each group). After 1 month survival after the BrdU injections (low dose), we noted that some cells exhibited dark and evenly stained immunoreactivity, whereas others exhibited light and only partially stained nuclear immunoreactivity (Fig. 3C). Light BrdU labeling is likely attributable to the loss of BrdU during a few rounds of cell division after BrdU incorporation (Takahashi et al., 1999). We excluded the lightly labeled cells compared between $1 \mathrm{~d}$ and 1 month survival. In 3-month-old WT mice, only $26 \%$ of $\mathrm{BrdU}^{+}$cells remained at 1 month versus $1 \mathrm{~d}$ survival (Fig. $3 B$ ). However, we found 6.5-fold more $\mathrm{BrdU}^{+}$cells in Bax-KO mice compared with WT littermates in the 1 month survival group, which is similar to the number of BrdU ${ }^{+}$ cells in the Bax-KO $1 \mathrm{~d}$ after the final BrdU injection. Although there are several factors that may affect the number of $\mathrm{BrdU}^{+}$ cells in this situation (such as continued proliferation of $\mathrm{BrdU}^{+}$cells or loss of BrdU integration during DNA repair), the increased persistence of $\mathrm{BrdU}^{+}$cells in the Bax-KO compared with WT mice is consistent with our argument that the PCD of newly generated neurons is absent in Bax-KO mice.

Because the number of light BrdU-labeled cells may be increased if more $\mathrm{BrdU}^{+}$cells proliferate after initial BrdU incorporation, we examined the ratio of dark- versus light-stained cells as an indication of the rate of proliferation (Fig. 3C). Approximately $56 \%$ of BrdU-labeled cells exhibited light BrdU-IR in both 

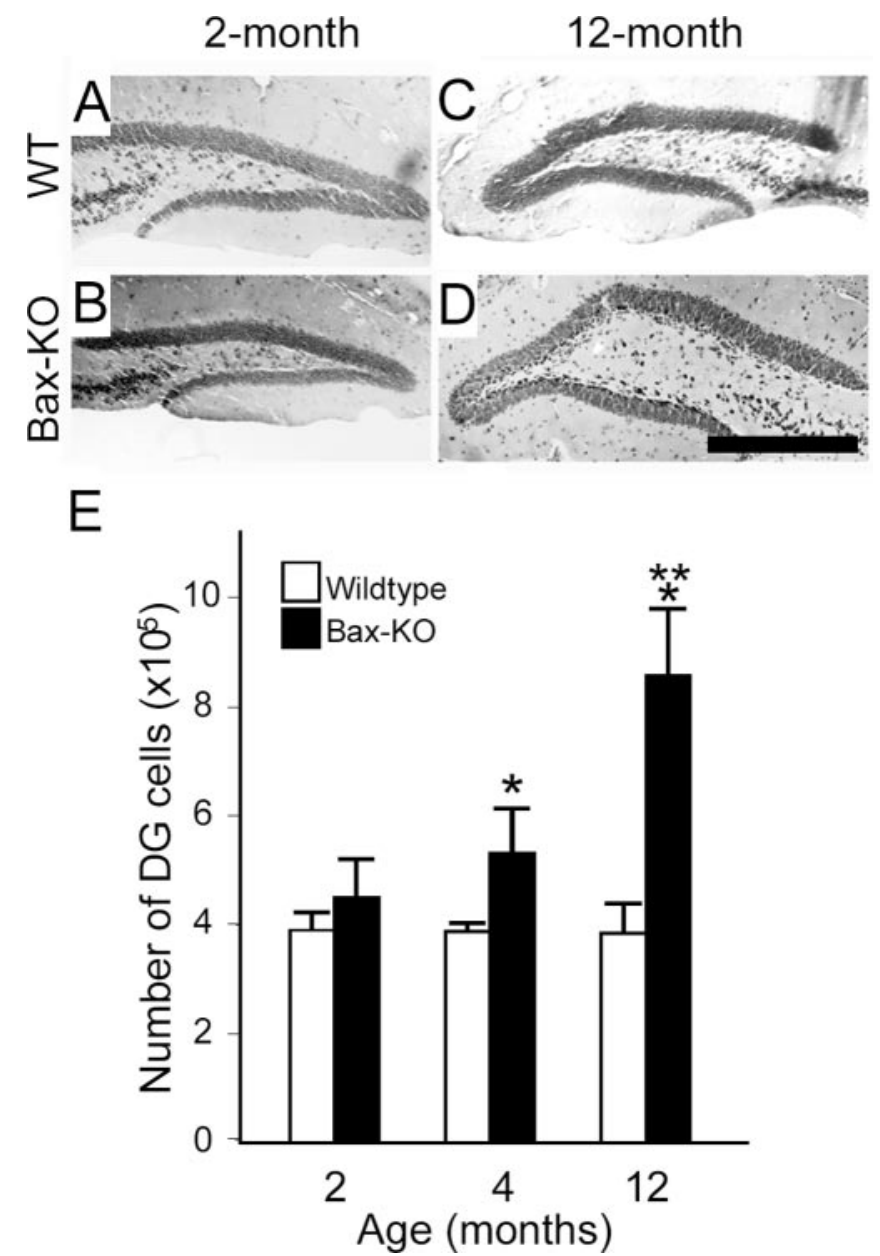

Figure 4. Age-dependent increase in the $D G$ volume in Bax-KO mice $(A-D)$. A, Two-month-old wild type; B, 2-month-old Bax-K0; C, 12-month-old wild type; D, 12-month-old Bax-KO. Scale bar, $500 \mu \mathrm{m}$. Representative Nissl-stained sections at a similar anatomical level (dorsal hippocampus) are presented. E, Number of DG neurons in WT and Bax-KO mice. The total number of DG neurons was estimated by measuring volume and cell density of DG neurons (see Materials and Methods). $n=$ $3-4$. Mean $\pm S D ;{ }^{*} p<0.05$ in $t$ test comparison of WT versus Bax-K0 mice. ${ }^{* *} p<0.05$ in $t$ test comparison of the 2 month versus the 12 month group in Bax-KO mice.

WT and Bax-KO mice. This suggests that the kinetics of cell proliferation is not influenced by the absence of adult PCD. Direct immunostaining of proliferating cells using a PCNA antibody (Fig. 3D) or a phosphorylated-histone $\mathrm{H} 3$ antibody (data not shown) also demonstrated similar numbers of labeled cells in the two groups. From these data, we conclude that the deletion of Bax does not modify the proliferation of adult neural stem cells in the DG.

The normal production of new cells in the absence of adult $\mathrm{PCD}$ in Bax-KO mice should result in an age-related increment in the number of neurons in the DG. To address this issue, we have estimated the total number of DG neurons present in 4- to 12 month-old mice (Fig. 4). At 2 months, when the accumulation of adult-generated neurons should be marginal, there was no significant difference in the cell number of DG cells in WT and Bax-KO mice. On the other hand, at 4 months, the total number of cells in the DG of Bax-KO mice was significantly greater than that of WT littermates. Furthermore, at 12 months, there was an even more marked increase in the cell numbers $\left(\sim 3 \times 10^{5}\right.$ cells, a $62 \%$ increase) compared with 4 -month-old Bax-KO mice. These data provide additional evidence consistent with the normal produc- tion of new neurons after the prevention of adult PCD by Bax deletion.

Ectopic migration of early postmitotic cells in Bax-KO mice During the course of BrdU-labeling experiments, we noticed that, compared with WT mice, more $\mathrm{BrdU}^{+}$cells appeared to be located deep inside the GCL and hilus in Bax-KO mice (Fig. 3A). Therefore, we examined whether the migration of adultgenerated neurons is affected by the absence of adult PCD (Fig. 5 ). We used DCX as a marker for neural stem cells and early migrating neurons (Brown et al., 2003). DCX-immunoreactive neurons were concentrated in proximity to the SGZ in both groups, as reported previously (Brown et al., 2003). However, we found that a subset of $\mathrm{DCX}^{+}$cells $\left(<5 \%\right.$ of all $\mathrm{DCX}^{+}$cells) was ectopically located in the hilus in the Bax-KO mice (Fig.

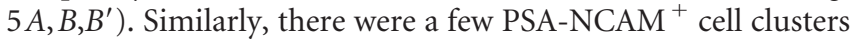
in the hilus of Bax-KO mice (Fig. $5 C, D$ ). Because PSA-NCAM is believed to label early migrating cells, these observations suggest that the migration of newly generated cells is perturbed in Bax-KO mice. In addition, there were significantly more DCX ${ }^{+}$ cells in the GCL of the 4-month-old Bax-KO compared with that of WT littermates, indicating that the survival of the early migrating neurons may be influenced by Bax deletion (Fig. $5 E$ ), which is consistent with the finding that, in WT animals, early postmitotic neurons exhibited Bax-IR (Fig. 2). The ectopically located cells in the Bax-KO appeared to differentiate into a neuronal phenotype based on the expression of NeuN (data not shown) and CB (Fig. $6 D$, arrows).

\section{Differentiation of DG neurons in Bax-KO mice}

Next, we examined whether the Bax-KO DG contains more cells exhibiting a marker (NeuN) for mature neurons (Fig. 6). The total number of $\mathrm{NeuN}^{+}$cells in 4-month-old Bax-KO mice was significantly greater than that in age-matched WT mice (Fig. 6 F), indicating that the Bax-KO-rescued, adult-generated DG cells can express a neuronal phenotype. To assess the differentiation of newly generated cells rescued from PCD in Bax-KO mice, we examined $\mathrm{BrdU}^{+}$cells for the expression of specific neuronal or glial markers 1 month after their generation (Fig. 6). In both WT and Bax-KO mice, the majority of surviving BrdU ${ }^{+}$cells $(\sim 65 \%)$ expressed the differentiated neuronal marker NeuN, 15\% were $\mathrm{GFAP}^{+}$, and the remaining cells were not labeled by either marker (i.e., there was no significant alteration in the ratio of $\mathrm{NeuN}^{+} / \mathrm{GFAP}^{+} / \mathrm{NeuN}-\mathrm{GFAP}^{-}$cells among the $\mathrm{BrdU}^{+}$cells between WT and Bax-KO littermates). These results suggest that the phenotypic (neuronal vs glial) fate of adult-generated cells is strictly maintained even in the absence of adult PCD.

To further assess whether Bax-KO DG neurons differentiate normally, we examined the expression of the mature phenotypic marker CB in 4-month-old Bax-KO mice (Fig. 7). Surprisingly, only a small subpopulation of DG neurons was $\mathrm{CB}^{+}$in 4-monthold Bax-KO mice. Many cells located near to the SGZ and proximal to the outer boundary of the molecular layer were $\mathrm{CB}^{-}$. The reduced number of $\mathrm{CB}^{+}$cells is not attributable to poor immunostaining, because CB-IR in the CA1 region and cerebellum did not differ in the two groups (data not shown). Furthermore, 1-month-old Bax-KO mice exhibited a normal WT-like pattern of $\mathrm{CB}$ immunostaining (Fig. 7, compare $A, B$, insets), suggesting that the loss of CB-IR in Bax-KO takes place later in development. To address whether it is the newly generated, Bax-KO-rescued neurons that fail to express $\mathrm{CB}$, we performed $\mathrm{BrdU}$ and $\mathrm{CB}$ double labeling 1 month after animals received five consecutive BrdU injections (Fig. $7 C, D$ ). Whereas $~ 50 \%$ of $\mathrm{BrdU}^{+}$cells were 


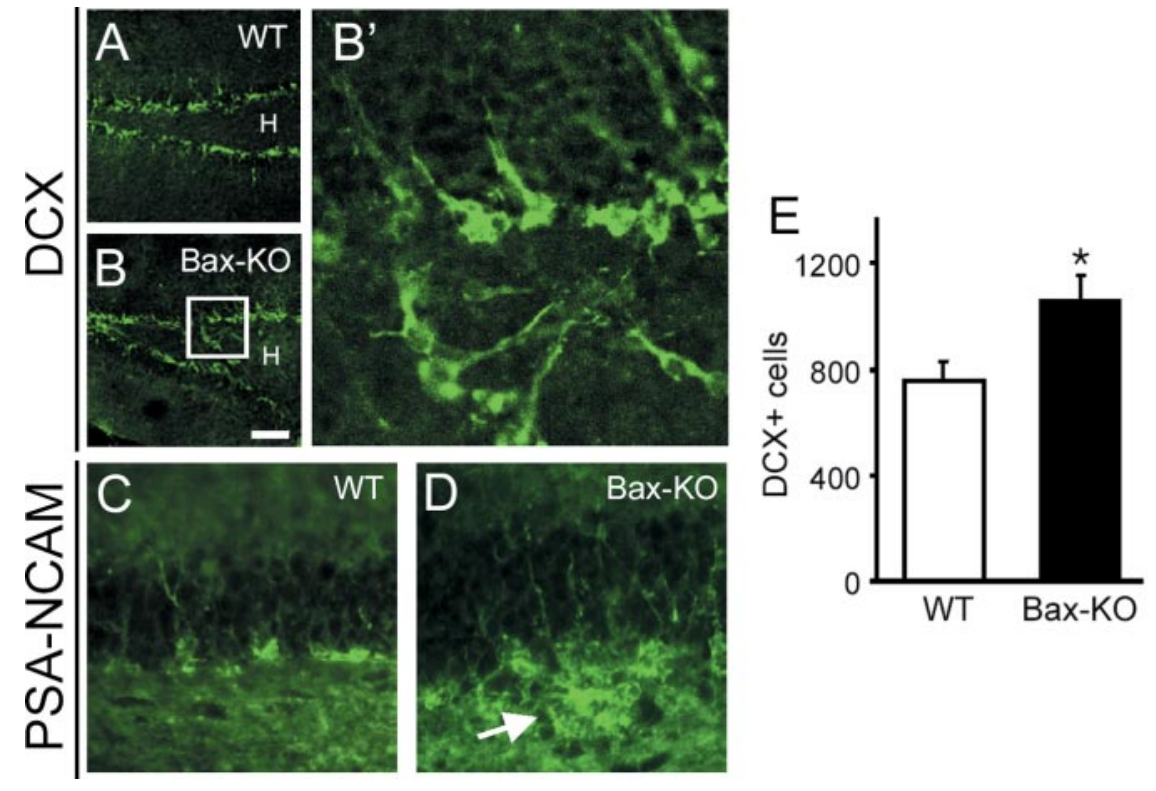

Figure 5. Immunohistochemical labeling of migrating neurons by $D C X(A, B)$ and PSA-NCAM $(C, D)$ demonstrates the ectopic migration of adult-generated neurons in Bax-KO mice. Whereas $D C X^{+}$cells were located near the SGZ in WT mice $(A)$, a subset of $\mathrm{DCX}{ }^{+}$neurons was observed in the hilus of the Bax-K0 mice ( $\left.B\right)$. Scale bar, $100 \mu \mathrm{m}$. H indicates the hilar region of the hippocampal formation. Increased magnification of the boxed area in $B$ clearly demonstrates ectopically migrated cells $\left(B^{\prime}\right)$. Similarly, there was ectopic localization of PSA-NCAM ${ }^{+}$cells in the hilus (arrow, D). E, Quantification of the DCX ${ }^{+}$cells in the DG. DCX ${ }^{+}$cells in every sixth section of DG were counted from four different animals (ectopically localized DCX ${ }^{+}$cells outside of GCL were excluded).

$\mathrm{CB}^{+}$in WT mice, only $5 \%$ of $\mathrm{BrdU}^{+}$cells were $\mathrm{CB}^{+}$in the Bax-KO littermates, suggesting that most adult-generated, BaxKO-rescued DG neurons fail to express the mature DG neuron marker $\mathrm{CB}$. However, because Bax-KO mice have increased numbers of $\mathrm{BrdU}^{+}$cells (no cell death), the total number of $\mathrm{CB}^{+} / \mathrm{BrdU}^{+}$cells in the two groups was comparable (Fig. $7 F$ ). These data indicate that equivalent numbers of adult-generated neurons can differentiate into mature neurons in the presence or absence of Bax, whereas most of the excess DG neurons rescued from PCD fail to differentiate into mature neurons.

Recently, it has been reported that a subset of neurons in the DG transiently express CR before they express CB (Brandt et al., 2003). Therefore, we examined whether the large number of $\mathrm{CB}^{-}$ cells in Bax-KO mice is attributable to the accumulation of $\mathrm{CR}^{+}$ cells (Fig. 6G,H). In WT mice, most $\mathrm{CR}^{+}$cells were located in proximity to the SGZ. In contrast, many $\mathrm{CR}^{+}$cells were found in the middle region of the GCL in Bax-KO mice (Fig. $6 F$, arrowhead), and the number of $\mathrm{CR}^{+}$cells was markedly increased (Fig. 7I). By using double-immunofluorescence labeling for $\mathrm{CB}$ and $\mathrm{CR}$, however, we found that $\mathrm{CR}^{+}$cells were not located in the outer region (in proximity to the molecular layer) of the GCL, in which many of the $\mathrm{CB}^{-}$cells reside in 4-month-old Bax-KO mice. These data indicate that the marked impairment of CB-IR in the DG of the Bax-KO cannot be explained solely by the accumulation of $\mathrm{CB}^{-} / \mathrm{CR}^{+}$adult-generated neurons. Therefore, we examined whether DG neurons generated earlier during development lose their CB-IR by 3 months in Bax-KO mice. Accordingly, we injected $\mathrm{BrdU}$ (50 $\mu \mathrm{g} / \mathrm{gm}$ ) once on postnatal day 3 (P3) and examined $\mathrm{CB}-\mathrm{IR}$ in $\mathrm{BrdU}^{+}$neurons at 1 and 3 months. As shown in Figure $8, \sim 56 \%$ of $\mathrm{BrdU}^{+}$cells in WT and Bax-KO mice were $\mathrm{CB}^{+}$after 1 month survival. On the other hand, 54\% of $\mathrm{BrdU}^{+}$neurons generated on $\mathrm{P} 3$ were $\mathrm{CB}^{+}$in WT mice, whereas only $17 \%$ of $\mathrm{BrdU}^{+}$neurons were $\mathrm{CB}^{+}$in Bax-KO mice after 3 month survival. Furthermore, many $\mathrm{CB}^{+}$neurons in Bax-KO mice exhibited a significantly reduced level of CB-IR, suggesting a marked downregulation of $\mathrm{CB}$ expression in the DG of the Bax-KO. Together, these observations indicate that the differentiation of Bax-KO DG neurons generated during development versus those generated in the adult is impaired in an age-dependent manner.

\section{Discussion \\ Adult PCD is mediated by Bax}

Several lines of evidence indicate that there is an absence or marked reduction of adult PCD in the Bax-KO mice: (1) TUNEL, activation of caspase-3, and nuclear pyknosis were never observed in the DG of adult Bax-KO mice; (2) the number of $\mathrm{BrdU}^{+}$ cells after $1 \mathrm{~d}$ versus 1 month survival was virtually the same in the DG of Bax-KO, whereas there was a $70 \%$ reduction of $\mathrm{BrdU}^{+}$cells during the same period in WT mice; and (3) there was a $62 \%$ increase in surviving DG neuron numbers between 4 and 12 months in Bax-KO mice, whereas the total number of DG neurons was unchanged in WT mice during the same period. These results indicate that Bax plays an indispensable role in the elimination of adult-generated neurons. Bax deletion also permanently rescues developing cells from target-dependent neuronal death (Deckwerth et al., 1996; White et al., 1998; Lentz et al., 1999; Sun et al., 2003). Targetderived trophic support is critical for the survival of developing neurons (Oppenheim, 1991; Grieshammer et al., 1998), and neurotrophic factors also appear to regulate the production and survival of adult-generated neurons (Aberg et al., 2000; Lichtenwalner et al., 2001; Pencea et al., 2001; Jin et al., 2002). Our observations suggest that the PCD of adult-generated DG neurons takes place postmitotically and during their early maturation. Although the number of stem cells is not altered in the Bax-KO, the number of early postmitotic $\left(\mathrm{DCX}^{+}\right.$and $\left.\mathrm{CR}^{+}\right)$cells and differentiated neurons $\left(\mathrm{NeuN}^{+}\right)$is greatly increased in the absence of PCD. In addition Bax-IR was observed in a subpopulation of WT DG neurons with a morphology similar to early migrating neurons. Therefore, adult-generated neurons most likely undergo PCD during their early differentiation. These apparent similarities in developmental and adult neuronal PCD suggest that the mechanisms that regulate both phases of PCD (e.g., competition for trophic support, proapoptotic and antiapoptotic pathways, etc.) may be the same.

It is puzzling why the number of $\mathrm{BrdU}^{+}$cells $(6000$ cells $1 \mathrm{~d}$ after five consecutive daily injections) is so great when compared with the actual age-dependent increase in the number of DG neurons ( $\sim 300,000$ cells between 4 and 12 months) in Bax-KO mice. Because a single injection of BrdU labels S-phase cells in 2 hr windows, we expected that $>10,000$ cells would be born daily. If all of these newly generated cells survive, $\sim 300,000$ cells would accumulate in Bax-KO DG within 1 month. Although we arbitrarily divided $\mathrm{BrdU}^{+}$cells into two categories (dark vs light labeling) for quantification, we actually observed an apparent continuum of BrdU staining intensity within each group (data not shown), indicating that there may be several rounds of cell division after BrdU incorporation that would greatly amplify the estimated number of newly generated cells (Rakic, 2002). If we 


\section{NeuN/BrdU}
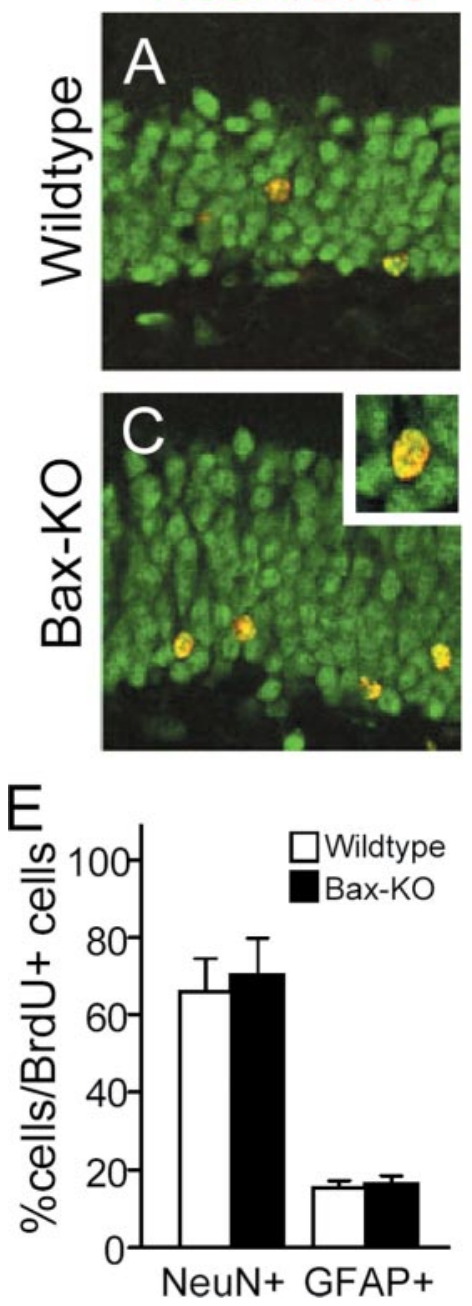

Figure 6. Differentiation of adult-generated neurons in 4-month-old Bax-KO mice. Animals received BrdU daily for $5 \mathrm{~d}$ and were killed $30 \mathrm{~d}$ later. BrdU ${ }^{+}$cells (red) were double labeled with the neuronal maker NeuN (green, $A, C$ or the glial marker GFAP (green, $B, D)$ in WT $(A, B)$ and Bax-KO ( $C$, $D$ ). Insets in $($ and $D$ show examples of double-labeled cells. Scale bar, $50 \mu \mathrm{m}$. $E$, The number of double-labeled cells was quantified from six sections in each of three mice, and $>200$ BrdU-labeled cells in each animal were examined. $F$, The number of $\mathrm{NeuN}^{+}$cells in a $200 \mu \mathrm{m}$ length of WT and Bax-KO DG. Mean $\pm S D ;{ }^{*} p<0.05$ in $t$ test comparison of WT versus Bax-K0 mice.

assume that the PCD of adult-generated neurons is completely absent in Bax-KO mice and that the production of new neurons is not influenced by Bax deletion, then $\sim 1300$ new neurons would be produced daily and added to the Bax-KO DG between 2 and 12 months for a total of $\sim 400,000$ new cells. Although we cannot completely exclude the possibility that adult-produced neurons in Bax-KO mice die by a non-apoptotic, Bax-independent pathway (Oppenheim et al., 2001), we consider this unlikely. We have so far failed to observe cells in the DG of Bax-KO mice that exhibit such a non-apoptotic morphology (R. W. Oppenheim, unpublished observations).

\section{Proliferation is not directly altered by the elimination of PCD by Bax deletion}

Because brain regions in which adult PCD occurs includes those areas in which adult neurogenesis takes place, it has been postulated that the proliferation of neural stem cells and PCD are causally related (Biebl et al., 2000; Winner et al., 2002). For instance, experimental increases in the PCD of adult DG cells induced by adrenalectomy and excitotoxic or mechanical lesions increases neurogenesis (Cameron and Gould, 1994; Liu et al., 1998; Yoshimura et al., 2001), and experimentally induced apoptosis also selectively increases the number of adult-generated neurons (Magavi et al., 2000). Conversely, experimental inhibition of adult neural stem cell proliferation by injection of a mitotic inhibitor increases the survival rate of the progeny (Ciaroni et al., 2002). In contrast, our observations do not support such a relationship. In the absence of adult PCD in Bax-KO mice, stem cell proliferation in the DG occurs at a rate comparable with WT littermates, indicating that spontaneous PCD and the production of new neurons are not directly linked in the normal adult brain (Verney et al., 2000).

It is important to note that the cell death of developing neuroepithelial cells does not appear to be affected by Bax deletion (White et al., 1998; D’Sa-Eipper et al., 2001). The developmental death of proliferating neural progenitors in the vicinity of the ventricular zone (cortex) and the external granule cell layers of cerebellum is not significantly affected by Bax deletion (White et al., 1998) (our unpublished observations). Recently, it has been reported that, in Bax and Bak double mutants, there is increased survival of adult neural progenitor cells as well as their neuronal progeny in the subventricular zone (SVZ) (Lindsten et al., 2003). When considered together with our present observations, these data raise the possibility that the PCD of adult dividing stem cells requires additional proapoptotic genes such as Bak, in addition to Bax, whereas the PCD of postmitotic differentiating adultgenerated neurons only requires Bax.

\section{The influence of PCD on the migration of} adult-generated neurons

One intriguing finding in this study is the apparent ectopic migration of adult-generated neurons to the hilus in 4-month-old Bax-KO mice. These ectopically migrated neurons appear otherwise normal, in that they express the mature DG neuronal marker calbindin. Furthermore, from our own preliminary observations of the rostral migratory stream (RMS), which is a route for the migration of adult-generated neurons to the olfactory bulb, cells in the RMS also exhibit aberrant migratory patterns in the Bax-KO mice (Lindsten et al., 2000). After the experimental induction of cell death in non-neurogenic areas of the brain, there is a significant ectopic migration of SVZ-generated neurons to these regions (Magavi et al., 2000; Nakatomi et al., 2002; Jin et al., 2003). Therefore, spontaneous PCD in the adult brain may also provide a signal for neuronal migration, and, accordingly, the loss of adult PCD in the adult Bax-KO may alter guidance signals for the proper migration of newly generated cells. Although there are only a few reports addressing the cues for migration of adult produced neurons, Reelin, tenascin-R, slits, and PSA-NCAM are reported to be important signals for the migration of adultgenerated neurons along the RMS and in the olfactory bulb $(\mathrm{Hu}$ et al., 1996; Hack et al., 2002; Nguyen-Ba-Charvet et al., 2004; Saghatelyan et al., 2004), and these molecules may be perturbed in the DG of the Bax-KO (Bagri et al., 2002; Drakew et al., 2002). Alternative explanations for migration deficits include the following: (1) Bax-KO-rescued cells may not be able to recognize normal migration cues and consequently migrate to ectopic locations; and (2) A subset of granule cell progenitors may be localized in the hilus in the Bax-KO mice attributable to the ectopic migration of $\mathrm{DCX}^{+}$progenitors during earlier development (Brown et al., 2003). Although we are unable to distinguish between these possibilities, the latter possibility seems unlikely, because ectopic localization of $\mathrm{DCX}^{+}$cells was not observed in 

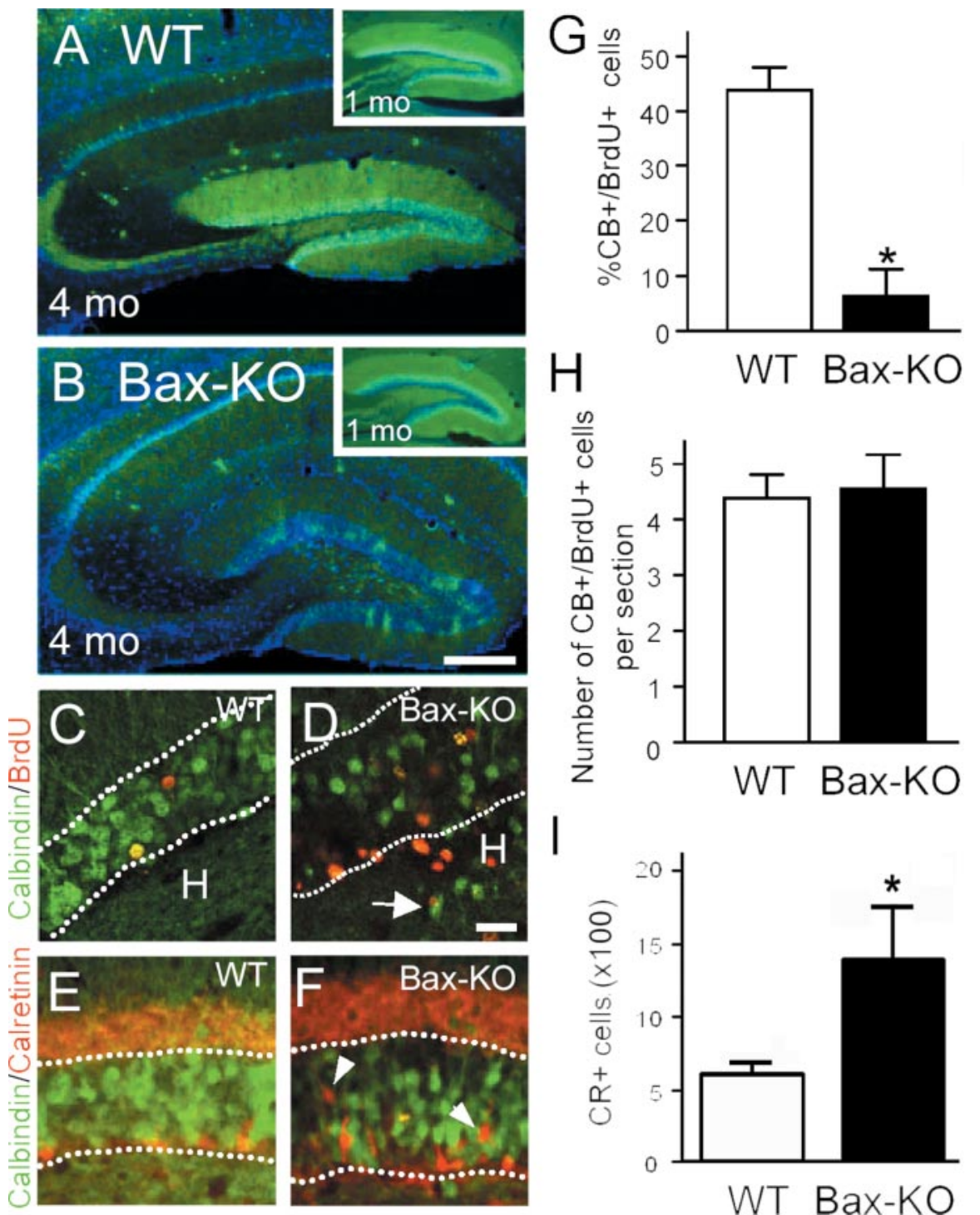

Figure 7. Reduction of (B immunoreactivity (green) in 4-month-old Bax-K0 mice (A, WT versus $B$, Bax-K0). Insets in $A$ and $B$ demonstrate an apparent normal pattern of CB-IR in 1-month-old WT and Bax-KO mice. Nuclei were visualized by Hoechst33342 (blue). Scale bar, $200 \mu \mathrm{m}$. C, D, One month after BrdU injection, BrdU ${ }^{+}$cells (red) double labeled with CB (green) were visualized. Note that most $\mathrm{BrdU}^{+}$cells in the Bax-K0 mice were $\mathrm{CB}^{-}$. Dotted lines indicate the boundary of the $\mathrm{GCL}$. Scale bar, $50 \mu \mathrm{m}$. Arrow in $D$ indicates $C B{ }^{+}$neurons localized in the hilus. $E, F$, Double labeling for $C B$ (green) and $C R$ (red) in 4-month-old WT $(E)$ and Bax-KO (F) mice. In the Bax-KO, there were many $C \mathrm{R}^{+}$cells in the middle of the $\mathrm{GCL}$ (arrowhead). G, Quantification of the percentage of double-labeled cells in the two groups. More than $200 \mathrm{BrdU}$-labeled cells from a similar region (caudal hippocampal) were examined per mouse. ${ }^{*} p<0.05$ in $t$ test comparison of WT versus Bax-KO mice. $H$, The number of double-labeled cells per section in the DG. I, The total number of $\mathrm{CR}^{+}$cells in every sixth section through the $\mathrm{DG}(n=4)$.

2-month-old Bax-KO mice (data not shown), indicating that there is no ectopic migration of neuronal progenitor cells during development.

\section{The influence of PCD on the differentiation of adult-generated neurons}

We found that many DG neurons in the Bax-KO expressed the differentiated neuronal marker NeuN but failed to express the mature DG neuronal marker CB. By separately labeling adultgenerated neurons versus developmentally generated neurons by BrdU injection, it was possible to demonstrate that both populations of neurons become $\mathrm{CB}^{-}$in the $\mathrm{Bax}-\mathrm{KO}$ mice. Because it is believed that the majority of the developmentally generated cohort of DG neurons that survive into the adult persist and do not die (Gould and Gross, 2002; Dayer et al., 2003), it is likely that the excess number of adult-generated neurons in the Bax-KO negatively influenced the maintenance of a mature neuronal phenotype. This situation could occur within the framework of a modified version of the neurotrophic hypothesis. Excess numbers of immature, adult-generated neurons in Bax-KO mice may increase the competition for trophic signals required for the maintenance of a mature DG neuronal phenotype (Minichiello and Klein, 1996). For example, during the development of spinal MNs in Bax-KO mice, we found that many of the excess Bax-KO-rescued MNs were smaller than normal, and they progressively retracted their axons from muscle innervation (Sun et al., 2003). Therefore, our model for the progressive atrophy of Bax-KO-rescued MNs, which is based on the neurotrophic hypothesis, could also explain why developmentally generated DG neurons lose their differentiated phenotype.

Recently, it was reported that a subset of dopaminergic neurons in the adult rat substantia nigra are continuously degenerating and are replaced by new neurons such that the total net number of DA neurons remains constant (Zhao et al., 2003). Similarly, $\sim 26 \%$ of the developmentally produced DG neurons in the rat progressively undergo cell death between 1 and 6 months of age (Dayer et al., 2003). These observations raise the possibility that a subset of mature developmentally generated DG neurons are continuously degenerating and being replaced by newly produced neurons in normal adult rodents, similar to the situation with adultgenerated olfactory neurons (Biebl et al., 2000; Kato et al., 2001; Petreanu and Alvarez-Buylla, 2002). This could explain why developmentally generated DG neurons in the Bax-KO progressively lose CBIR. Bax deletion would prevent the progressive normal PCD of developmentally produced DG neurons, and these Bax-KOrescued neurons may fail to maintain a mature neuronal phenotype and thus lose CB-IR. This replacement hypothesis can also explain why the total number of DG neurons does not increase between 2 and 12 months in WT mice (present data) in the face of the addition of a significant number of new neurons during this period. Accordingly, although the mechanism is unclear, our results suggest that spontaneous PCD in the adult brain may be necessary for the maintenance of the mature neuronal phenotype in surviving cells.

\section{References}

Aberg MA, Aberg ND, Hedbacker H, Oscarsson J, Eriksson PS (2000) Peripheral infusion of IGF-I selectively induces neurogenesis in the adult rat hippocampus. J Neurosci 20:2896-2903. 
Abercrombie M (1946) Estimation of nuclear population from microtome sections. Anat Rec 94:239-247.

Bagri A, Gurney T, He X, Zou Y-R, Littman DR, Tessier-Lavigne M, Pleasure SJ (2002) The chemokine SDF1 regulates migration of dentate granule cells. Development 129:4249-4260.

Biebl M, Cooper CM, Winkler J, Kuhn HG (2000) Analysis of neurogenesis and programmed cell death reveals a self-renewing capacity in the adult rat brain. Neurosci Lett 291:17-20.

Brandt MD, Jessberger S, Steiner B, Kronenberg G, Reuter K, Bick-Sander A, von der Behrens W, Kempermann G (2003) Transient calretinin expression defines early postmitotic step of neuronal differentiation in adult hippocampal neurogenesis of mice. Mol Cell Neurosci 24:603-613.

Brown JP, Couillard-Despres S, Cooper-Kuhn CM, Winkler J, Aigner L, Kuhn HG (2003) Transient expression of doublecortin during adult neurogenesis. J Comp Neurol 467:1-10.

Cameron HA, Gould E (1994) Adult neurogenesis is regulated by adrenal steroids in the dentate gyrus. Neuroscience 61:203-209.

Cameron HA, McKay RD (2001) Adult neurogenesis produces a large pool of new granule cells in the dentate gyrus. J Comp Neurol 435:406-417.

Ciaroni S, Cecchini T, Ferri P, Ambrogini P, Cuppini R, Riccio M, Lombardelli G, Papa S, Del Grande P (2002) Impairment of neural precursor proliferation increases survival of cell progeny in the adult rat dentate gyrus. Mech Ageing Dev 123:1341-1352.

Clarke PG, Oppenheim RW (1995) Neuron death in vertebrate development: in vivo methods. Methods Cell Biol 46:277-321.

Dayer AG, Ford AA, Cleaver KM, Yassaee M, Cameron HA (2003) Shortterm and long-term survival of new neurons in the rat dentate gyrus. J Comp Neurol 460:563-572.

Deckwerth TL, Elliott JL, Knudson CM, Johnson Jr EM, Snider WD, Korsmeyer SJ (1996) BAX is required for neuronal death after trophic factor deprivation and during development. Neuron 17:401-411.

Drakew A, Deller T, Heimrich B, Gebhardt C, Del Turco D, Tielsch A, Forster E, Herz J, Frotscher M (2002) Dentate granule cells in reeler mutants and VLDLR and ApoER2 knockout mice. Exp Neurol 176:12-24.

D'Sa-Eipper C, Leonard JR, Putcha G, Zheng TS, Flavell RA, Rakic P, Kuida K, Roth KA (2001) DNA damage-induced neural precursor cell apoptosis requires p53 and caspase 9 but neither Bax nor caspase 3. Development 128:137-146.

Eriksson PS, Perfilieva E, Bjork-Eriksson T, Alborn AM, Nordborg C, Peterson DA, Gage FH (1998) Neurogenesis in the adult human hippocampus. Nat Med 4:1313-1317.

Gould E, Gross CG (2002) Neurogenesis in adult mammals: some progress and problems. J Neurosci 22:619-623.

Gould E, McEwen BS, Tanapat P, Galea LA, Fuchs E (1997) Neurogenesis in the dentate gyrus of the adult tree shrew is regulated by psychosocial stress and NMDA receptor activation. J Neurosci 17:2492-2498.

Grieshammer U, Lewandoski M, Prevette D, Oppenheim RW, Martin GR (1998) Muscle-specific cell ablation conditional upon Cre-mediated DNA recombination in transgenic mice leads to massive spinal and cranial motoneuron loss. Dev Biol 197:234-247.

Guillery RW, Herrup K (1997) Quantification without pontification: choosing a method for counting objects in sectioned tissues. J Comp Neurol 386:2-7.

Hack I, Bancila M, Loulier K, Carroll P, Cremer H (2002) Reelin is a detachment signal in tangential chain-migration during postnatal neurogenesis. Nat Neurosci 5:939-945.

Horner PJ, Power AE, Kempermann G, Kuhn G, Palmer TD, Winkler J, Thal LJ, Gage FH (2000) Proliferation and differentiation of progenitor cells throughout the intact adult rat spinal cord. J Neurosci 20:2218-2228.

Hu H, Tomasiewicz H, Magnuson T, Rutishauser U (1996) The role of polysialic acid in migration of olfactory bulb interneuron precursors in the subventricular zone. Neuron 16:735-743.

Jin K, Mao XO, Sun Y, Xie L, Greenberg DA (2002) Stem cell factor stimulates neurogenesis in vitro and in vivo. J Clin Invest 110:311-319.

Jin K, Sun Y, Xie L, Peel A, Mao XO, Batteur S, Greenburg DA (2003) Direct migration of neuronal precursors into the ischemic cerebral cortex and striatum. Mol Cell Neurosci 24:171-189.

Kaplan MS, Hinds JW (1977) Neurogenesis in the adult rat: electron microscopic analysis of light radioautographs. Science 197:1092-1094.

Kaplan MS, McNelly NA, Hinds JW (1985) Population dynamics of adultformed granule neurons of the rat olfactory bulb. J Comp Neurol 239:117-125.

Kato T, Yokouchi K, Fukushima N, Kawagishi K, Li Z, Moriizumi T (2001) Continual replacement of newly-generated olfactory neurons in adult rats. Neurosci Lett 307:17-20.

Kempermann G, Kuhn HG, Gage FH (1997) More hippocampal neurons in adult mice living in an enriched environment. Nature 386:493-495.

Kintner C (2002) Neurogenesis in embryos and in adult neural stem cells. J Neurosci 22:639-643.

Knudson CM, Tung KS, Tourtellotte WG, Brown GA, Korsmeyer SJ (1995) Bax-deficient mice with lymphoid hyperplasia and male germ cell death. Science 270:96-99.

Kornack DR, Rakic P (1999) Continuation of neurogenesis in the hippocampus of the adult macaque monkey. Proc Natl Acad Sci USA 96:5768-5773.

Lentz SI, Knudson CM, Korsmeyer SJ, Snider WD (1999) Neurotrophins support the development of diverse sensory axon morphologies. J Neurosci 19:1038-1048.

Lichtenwalner RJ, Forbes ME, Bennett SA, Lynch CD, Sonntag WE, Riddle DR (2001) Intracerebroventricular infusion of insulin-like growth factor-I ameliorates the age-related decline in hippocampal neurogenesis. Neuroscience 107:603-613.

Lindsten T, Ross AJ, King A, Zong W-X, Rathmell JC, Shiels HA, Ulrich E, Waymire KG, Mahar P, Frauwirth K, Chen Y, Wei M, Eng VM, Adelman DM, Simon MC, Ma A, Golden JA, Evan G, Korsmeyer SJ, MacGregor GR, Thompson CB (2000) The combined functions of proapoptotic Bcl-2 family members Bak and Bax are essential for normal development of multiple tissues. Mol Cell 6:1389-1399.

Lindsten T, Golden JA, Zong W-X, Manarcik J, Harris MH, Thompson CB (2003) The proapoptotic activities of Bax and Bak limits the size of the neural stem cell pool. J Neurosci 23:11112-11119.

Liu J, Solway K, Messing RO, Sharp FR (1998) Increased neurogenesis in the dentate gyrus after transient global ischemia in gerbils. Neuroscience 18:7768-7778.

Magavi SS, Leavitt BR, Macklis JD (2000) Induction of neurogenesis in the neocortex of adult mice. Nature 405:951-955. 
Minichiello L, Klein R (1996) TrkB and TrkC neurotrophin receptors cooperate in promoting survival of hippocampal and cerebellar granule neurons. Genes Dev 10:2849-2858.

Nakatomi H, Kuriu T, Okabe S, Yamamoto S, Hatano O, Kawahara N, Tamura A, Kirino T, Nakafuku M (2002) Regeneration of hippocampal pyramidal neurons after ischemic brain injury by recruitment of endogenous neural progenitors. Cell 110:429-441.

Nguyen-Ba-Charvet KT, Picard-Riera N, Tessier-Lavigne M, Baron-Van Evercooren A, Sotelo C, Chedotal A (2004) Multiple roles for slits in the control of cell migration in the rostral migratory stream. J Neurosci 24:1497-1506.

Oppenheim RW (1991) Cell death during development of the nervous system. Annu Rev Neurosci 14:453-501.

Oppenheim RW, Flavell RA, Vinsant S, Prevette D, Kuan CY, Rakic P (2001) Programmed cell death of developing mammalian neurons after genetic deletion of caspases. J Neurosci 21:4752-4760.

Pencea V, Bingaman KD, Wiegand SJ, Luskin MB (2001) Infusion of brainderived neurotrophic factor into the lateral ventricle of the adult rat leads to new neurons in the parenchyma of the striatum, septum, thalamus, and hypothalamus. J Neurosci 21:6706-6717.

Petreanu L, Alvarez-Buylla A (2002) Maturation and death of adult-born olfactory bulb granule neurons: role of olfaction. J Neurosci 22:6106-6113.

Rakic P (2002) Adult neurogenesis in mammals: an identity crisis. J Neurosci 22:614-618.

Saghatelyan A, De Chevigny A, Schachner M, Lledo PM (2004) Tenascin-R mediates activity-dependent recruitment of neuroblasts in the adult mouse forebrain. Nat Neurosci 7:347-356.

Sekerkova G, Ilijic E, Mugnaini E (2004) Bromodeoxyuridine administered during neurogenesis of the projection neurons causes cerebellar defects in rat. J Comp Neurol 470:221-239.
Sun W, Oppenheim RW (2003) Response of motoneurons to neonatal sciatic nerve axotomy in Bax-knockout mice. Mol Cell Neurosci 24:875-886.

Sun W, Gould TW, Vinsant S, Prevette D, Oppenheim RW (2003) Neuromuscular development after the prevention of naturally occurring neuronal death by Bax deletion. J Neurosci 23:7298-7310.

Takahashi T, Goto T, Miyama S, Nowakowski RS, Caviness VS Jr (1999) Sequence of neuron origin and neocortical laminar fate: relation to cell cycle of origin in the developing murine cerebral wall. J Neurosci 19:10357-10371.

Verney C, Takahashi T, Bhide PG, Nowakowski RS, Caviness VS (2000) Independent controls for neocortical neuron production and histogenetic cell death. Dev Neurosci 22:125-138.

White FA, Keller-Peck CR, Knudson CM, Korsmeyer SJ, Snider WD (1998) Widespread elimination of naturally occurring neuronal death in Baxdeficient mice. J Neurosci 18:1428-1439.

Winner B, Cooper-Kuhn CM, Aigner R, Winkler J, Kuhn HG (2002) Longterm survival and cell death of newly generated neurons in the adult rat olfactory bulb. Eur J Neurosci 16:1681-1689.

Yoshimura S, Takagi Y, Harada J, Teramoto T, Thomas SS, Waeber C, Bakowska JC, Breakefield XO, Moskowitz MA (2001) FGF-2 regulation of neurogenesis in adult hippocampus after brain injury. Proc Natl Acad Sci USA 98:5874-5879.

Young D, Lawlor PA, Leone P, Dragunow M, During MJ (1999) Environmental enrichment inhibits spontaneous apoptosis, prevents seizures and is neuroprotective. Nat Med 5:448-453.

Zhao M, Momma S, Delfani K, Carlen M, Cassidy RM, Johansson CB, Brismar H, Shupliakov O, Frisen J, Janson AM (2003) Evidence for neurogenesis in the adult mammalian substantia nigra. Proc Natl Acad Sci USA 100:7925-7930. 